\title{
Efficacy of transanal drainage tube and self-expanding metallic stent in acute left malignant colorectal obstruction
}

\author{
Yue An ${ }^{1}$, Ningning Wang ${ }^{1}$, Zhidong Yang ${ }^{2}$, Yue $\mathrm{Li}^{1}$, Boyang Xu ${ }^{1}$, Guangying Guo ${ }^{3}$, Mingjun Sun ${ }^{1}$ \\ ${ }^{1}$ Department of Gastroenterology, ${ }^{2}$ Department of Laboratory Medicine, ${ }^{3}$ Department of Nephrology, The First Hospital of China Medical \\ University, Shenyang, China \\ Contributions: (I) Conception and design: Y An, M Sun; (II) Administrative support: M Sun; (III) Provision of study materials or patients: N Wang, \\ Z Yang, Y Li; (IV) Collection and assembly of data: N Wang, Z Yang, Y Li; (V) Data analysis and interpretation: B Xu, G Guo; (VI) Manuscript \\ writing: All authors; (VII) Final approval of manuscript: All authors. \\ Correspondence to: Professor Mingjun Sun. Department of Gastroenterology, The First Hospital of China Medical University, 155 Nanjing Bei Road, \\ Shenyang 110001, China. Email: sunmjmw@163.com.
}

Background: The self-expanding metal stent (SEMS) or transanal drainage tube (TDT) methods can be used as a palliative treatment before tumor resection surgery. Studies systematically comparing the efficacy and characteristics between SEMS with TDT are limited, especially in a large-scale Chinese population. This retrospective study aimed to compare the outcomes of these treatment approaches.

Methods: This was a retrospective comparative study of patients with an acute malignant left colorectal obstruction who underwent a preoperative decompressive procedure with SEMS or TDT intervention between December 2014 and October 2017. The indicators after endoscopic treatment and tumor resection surgery between the SEMS and TDT groups were compared.

Results: 206 patients underwent endoscopic intervention to relieve obstruction, including 139 patients treated with SEMS and 67 patients treated with TDT. The technical success rates of the SEMS group and TDT group were $97.1 \%$ and $95.6 \%$, respectively, and the rates of obstruction relief were $92.8 \%$ and $86.6 \%$, respectively. TDT was more easily translocated than SEMS $(\mathrm{P}=0.02)$, and there was no significant difference in the incidence of other complications. However, SEMS had a lower complication rate than TDT $(\mathrm{P}=0.02)$, and could alleviate the obstruction faster $(\mathrm{P}<0.01)$. There were 72 patients and 44 patients who took resection surgery in the SEMS group and TDT group, respectively. The direct anastomosis rates were $73.6 \%$ and $63.6 \%(\mathrm{P}=0.26)$, respectively, and only 1 case in the TDT group had anastomotic leakage. The surgery time of the SEMS group was significantly shorter than that of the TDT group (P=0.01). There was no significant difference between the 2 groups in terms of postoperative hospital stay $(\mathrm{P}=1.00)$ or total treatment costs for patients undergoing surgery $(\mathrm{P}=0.26)$.

Conclusions: Both TDT and SEMS could effectively relieve acute left malignant colorectal obstruction with safe and reliable results, and they could both reduce the stomas rate compared with traditional surgery. SEMS could alleviate obstruction faster than TDT and had fewer complications.

Keywords: Colorectal cancer (CRC); acute left malignant colorectal obstruction; transanal drainage tube (TDT); self-expanding metallic stent (SEMS)

Submitted Nov 05, 2019. Accepted for publication May 28, 2020.

doi: $10.21037 / \mathrm{apm}-19-458$

View this article at: http://dx.doi.org/10.21037/apm-19-458 


\section{Introduction}

Colorectal cancer (CRC) is a severe threat to human health. The latest data show that there were about 1.80 million new cases of CRC worldwide in 2018 (1). Among these CRC patients, approximately $7-29 \%$ of patients were discovered with subtotal or total bowel obstruction as the first symptom (especially on the left side) (2-4). The general condition for these patients is reduced, and CRC is often accompanied by many syndromes such as electrolyte imbalance, dehydration, and anemia, which are difficult to correct in a short period, resulting in poor surgical tolerance. For example, the edema of the intestinal wall and the dilation of the proximal intestine increase the likelihood of anastomotic leak (5). Overall, these complications have substantially impacted patients' prognosis and survival (6). Therefore, it is necessary to explore a better way to treat malignant colorectal obstruction (MCO).

Traditionally, to treat MCO, emergency colostomy followed with stomas has been the preferred choice (7). However, this process was complicated and usually brought patients a substantial economic burden (8), with approximately 40 percent of patients having permanent stomas (9). To reduce the considerable risk and laborious process of the surgery, preoperative decompression was generally adopted, which included placement of a self-expanding metallic stent (SEMS) or a transanal drainage tube (TDT). Due to the appearance and application of SEMS and TDT, the rate of primary anastomosis has increased, which has made the alleviation a bridge to elective surgery and significantly reduced the incidence of various complications (10-15). Compared with an emergency colostomy, the mean decompression period of SEMS and TDT is visibly shorter.

In recent years, both SEMS and TDT have been applied in clinical practice and possess high technical success rates $(16,17)$. SEMS facilitates both the evaluation of the status of the patient's proximal colon and the relief of obstruction while permitting patients to intake food. Furthermore, SEMS allows relief of obstruction in palliative cases (18), which could lead to a better condition. As for TDT, it can be used flexibly and efficiently removed after the alleviation of the colorectal obstruction. Meanwhile, the material cost of the TDT is cheap. SEMS and TDT have their own merits and faults, and systematic comparisons between SEMS and TDT is needed to ensure their selection is suitable for a given patient. However, studies systematically comparing the efficacy and characteristics between SEMS with TDT are limited, especially in a large-scale Chinese population.
This study aimed to compare the efficacy and characteristics of SEMS and TDT in patients with malignant left colorectal obstruction. We also compared the short-term outcomes after a surgical operation for patients receiving SEMS or TDT. We present the following article in accordance with the STROBE Reporting Checklist (available at http://dx.doi.org/10.21037/apm-19-458).

\section{Methods}

\section{Patients}

This was a retrospective comparative study of patients with acute malignant left colorectal obstruction who underwent a preoperative decompressive procedure with SEMS or TDT intervention between December 2014 and October 2017 in the First Affiliated Hospital of China Medical University. The trial was conducted in accordance with the Declaration of Helsinki (as revised in 2013). The study was approved by the Regional and Institutional Human Medical Biological Research Ethics Committee of China Medical University (No. AF-SOP-07-1). Written informed consent was obtained from all patients included in our study.

Inclusion criteria were the presence of acute obstructive symptoms such as difficulty in defecating, accompanied by abdominal distension and pain, abdominal X-ray or abdominal computed tomography (CT) suggesting left colorectal obstruction and histology indicating cancer by endoscopic biopsy or postoperative pathology. Patients with peritonitis, bowel perforation, or necrosis were excluded. The selection of intervention depended simply on the period. From December 2014 to December 2015, TDT was the first-choice treatment. From 2016 onwards, we used SEMS for all cases, except for a small number of cases with surrounding abscess formation.

Eventually, 206 patients needed endoscopic intervention to relieve obstruction, with 139 being treated with SEMS and 67 being treated with TDT. All patients were treated by experienced endoscopic surgeons with standard oncological principles.

\section{Outcome measures}

The whole study was divided into 2 stages. The first stage was aimed to alleviate the obstruction condition by TDT or SEMS intervention, and to calculate the incidence of technique success, clinical success, complications, and reinterventions. Technical success was defined as the 
achievement of instrument placement. Clinical success was defined as the resolution of obstructive symptoms (abdominal distension, vomiting, abdominal pain, and no passage of gas or stool) along with technical success. The presence of complications was defined as the occurrence of symptoms, including obstruction, infection, displacement, perforation, etc. Reintervention was defined as the SEMS or TDT intervention being given again after the last intervention. The second stage focused on the followup treatment of patients, especially those who underwent surgical resection of the tumor, and aimed to calculate the operation time, postoperative hospitalization time, hospitalization cost, and incidence of anastomotic leakage.

\section{Placement of TDT}

For TDT, the guidewire was inserted through the narrow segment under endoscopy and X-ray monitoring, and the contrast agent was injected under fluoroscopy. After the stenosis section was confirmed with a radiocontrast agent, the TDT (CLINY, Create Medic, Japan) was placed following the guidewire crossing the narrow segment. After re-injection of contrast agent to confirm a proper TDT placement, we injected $30 \mathrm{ml}$ of water into the water sac to prevent migration.

\section{Placement of SEMS}

The placement of SEMS was guided under guidewire. The guidewire was inserted through the narrow segment under endoscopy and $\mathrm{X}$-ray monitoring, and the contrast agent was injected under fluoroscopy. After the stenosis section was confirmed with a radiocontrast agent, we choose the stent with a suitable length, which ran across the entire length of the stenosis over $2 \mathrm{~cm}$. Then, the SEMS (Boston Scientific Corp., USA) was placed following the guidewire that crossed the narrow segment. Finally, the contrast agent was injected to confirm the correct placement of the stent to expand the stenosis.

\section{Statistical analysis}

According to the distribution of the data, an independent $t$-test was used to compare the means of the continuous variables by mean \pm standard deviation. Mann-Whitney $U$ test was used in the non-normal distribution measurement data. The enumeration data were represented by the Chi-square test and Fisher's exact test with a constituent ratio. All $\mathrm{P}$ values were two-sided, and $\mathrm{P}<0.05$ was considered statistically significant. Statistical testing was done with SPSS version 17.0 (IBM, Armonk, NY, USA).

\section{Results}

\section{Patient characteristics}

To evaluate the quality of 2 interventions, we divided the 206 patients into 2 groups according to the decompression measures: 139 patients were in the SEMS group, and 67 patients were in the TDT group. The detailed process of our study design was shown in Figure 1 and the baseline characteristics of the included patients are shown in Table 1. There were no significant differences in sex, age, and site of tumor between the 2 groups.

\section{Technical and clinical success rates of each intervention}

Due to the location and morphology of the tumor, 4 patients and 3 patients did not complete the placement of SEMS or TDT, respectively. SEMS placement was successfully performed in 135 patients and was decompressed in 129 patients. Meanwhile, TDT placement was performed in 64 patients and was adequately decompressed in 58 patients. The technical success rates of the SEMS and TDT groups were $97.1 \%$ and $95.6 \%$, while the clinical success rates were $92.8 \%$ and $86.6 \%$, respectively (Table 2). Both technical $(\mathrm{P}=0.56)$ and clinical $(\mathrm{P}=0.15)$ success rates were not significantly different between the 2 groups.

\section{Complications after endoscopic treatment}

The complications after endoscopic treatment are summarized in Table 3. After successful SEMS or TDT implantation, $95.6 \%(129 / 135)$ and $85.9 \%(55 / 64)$ of the patients in the 2 groups, respectively, had no apparent complications. In the SEMS group, there were 2 cases of re-obstruction, 1 case of SEMS displacement, which was removed by endoscopy, 2 cases of diffuse peritonitis, and 1 case of perforation after stenting. In the TDT group, reobstruction occurred in 4 cases, which was relieved after SEMS, and there were 4 cases of TDT displacement and 1 case of perforation.

The displacement rates of the SEMS and TDT groups were $0.7 \%(1 / 135)$ and $6.3 \%(4 / 64)$, respectively. TDT was more prone to displacement than SEMS $(\mathrm{P}=0.02)$. There was no significant difference in the incidence of other 


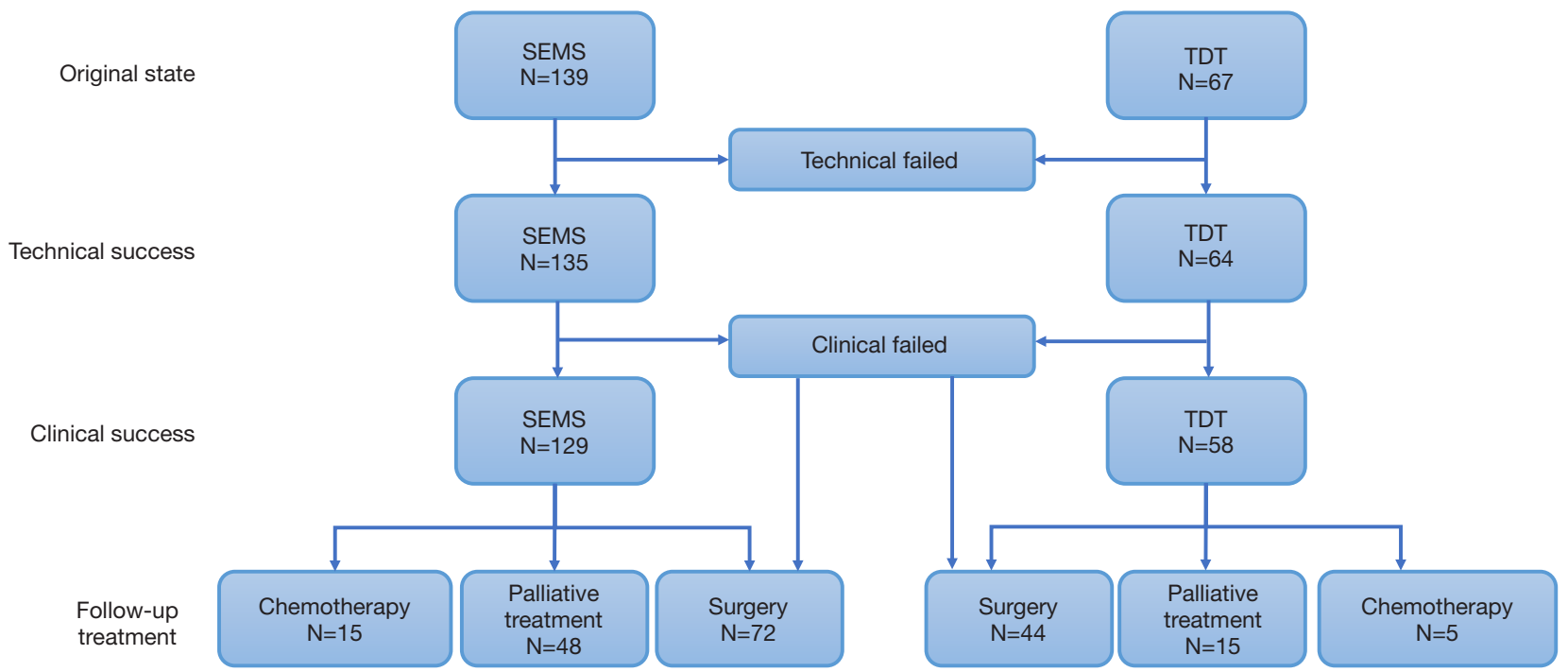

Figure 1 The flow diagraph of the study design.

Table 1 Basic characteristics of patients

\begin{tabular}{lccc}
\hline Variables & $\begin{array}{c}\text { SEMS } \\
(\mathrm{n}=139)\end{array}$ & $\begin{array}{c}\text { TDT } \\
(\mathrm{n}=67)\end{array}$ & P value* \\
\hline Age (y) & $67.9 \pm 12.5$ & $65.9 \pm 11.0$ & 0.27 \\
Sex & & & \\
Male (\%, n) & $61.2(85)$ & $64.2(43)$ & 0.68 \\
Female (\%, n) & $38.8(54)$ & $36.8(24)$ & \\
Tumor location & & & \\
Descending colon & $28.1(39)$ & $19.4(13)$ & 0.57 \\
Descending-sigmoid junction & $11.5(16)$ & $13.4(9)$ & \\
Sigmoid colon & $43.9(61)$ & $46.3(31)$ & \\
Rectum & $16.5(23)$ & $20.9(14)$ & \\
TNM stage & & & \\
II & $19.4(27)$ & $17.9(12)$ & 0.30 \\
III & $60.4(84)$ & $52.2(35)$ & \\
IV & $20.1(28)$ & $29.9(20)$ & \\
\hline
\end{tabular}

${ }^{*}$ Chi-squared test or $t$-test. SEMS, self-expanding metallic stent; TDT, transanal drainage tube.

complications such as infection and perforation, but the complication rate was higher in the TDT group overall $(\mathrm{P}=0.02$, Table 3).

Post-intervention oral feeding time in the SEMS group and TDT group was $2.4 \pm 1.5$ and $8.1 \pm 3.8$ days, respectively, and the time for oral feeding after SEMS implantation was
Table 2 Technical and clinical success rates for each intervention

\begin{tabular}{lccc}
\hline Variables & SEMS $(n=139)$ & TDT $(n=67)$ & P value $^{*}$ \\
\hline $\begin{array}{l}\text { Technical success rate } \\
(\%, n)\end{array}$ & $97.1(135)$ & $95.6(64)$ & 0.56 \\
$\begin{array}{l}\text { Clinical success rate } \\
(\%, n)\end{array}$ & $92.8(129)$ & $86.6(58)$ & 0.15 \\
\hline $\begin{array}{l}\text { *Chi-squared test. SEMS, self-expanding metallic stent; TDT, } \\
\text { transanal drainage tube. }\end{array}$
\end{tabular}

Table 3 Postoperative effect of each intervention

\begin{tabular}{|c|c|c|c|}
\hline Variables & $\begin{array}{l}\text { SEMS } \\
(n=135)\end{array}$ & $\begin{array}{c}\text { TDT } \\
(n=64)\end{array}$ & $P$ value \\
\hline \multicolumn{4}{|l|}{$\begin{array}{l}\text { Post-SEMS or TDT insertion } \\
\text { complications }\end{array}$} \\
\hline Re-obstruction rate $(\%, \mathrm{n})$ & $1.5(2)$ & $6.3(4)$ & 0.07 \\
\hline Infection rate $(\%, \mathrm{n})$ & $1.5(2)$ & $0(0)$ & 0.33 \\
\hline Displacement rate $(\%, \mathrm{n})$ & $0.7(1)$ & $6.3(4)$ & 0.02 \\
\hline Perforation rate $(\%, \mathrm{n})$ & $0.7(1)$ & $1.6(1)$ & 0.59 \\
\hline Non-complications rate $(\%, \mathrm{n})$ & $95.6(129)$ & $85.9(55)$ & 0.02 \\
\hline $\begin{array}{l}\text { Post intervention oral feeding } \\
\text { time(day) }\end{array}$ & $2.4 \pm 1.5$ & $8.1 \pm 3.8$ & 0.00 \\
\hline $\begin{array}{l}\text { Time interval between SEMS/ } \\
\text { TDT insertion and surgery }\end{array}$ & $11.85 \pm 8.59$ & $9.11 \pm 4.91$ & 0.06 \\
\hline
\end{tabular}

${ }^{*}$ Chi-squared test or $t$-test. SEMS, self-expanding metallic stent; TDT, transanal drainage tube. 
Table 4 follow-up treatment after each intervention

\begin{tabular}{lccc}
\hline Variables & SEMS $(\mathrm{n}=135)$ & TDT $(\mathrm{n}=64)$ & $\mathrm{P} \mathrm{value}^{*}$ \\
\hline Surgery $(\%, \mathrm{n})$ & $53.3(72)$ & $68.8(44)$ & 0.12 \\
Chemotherapy $(\%, \mathrm{n})$ & $11.1(15)$ & $7.8(5)$ & \\
Palliative treatment $(\%, \mathrm{n})$ & $35.6(48)$ & $23.4(15)$ & \\
\hline
\end{tabular}

${ }^{*}$ Chi-squared test. SEMS, self-expanding metallic stent; TDT, transanal drainage tube.

Table 5 condition after surgical tumor resection

\begin{tabular}{|c|c|c|c|}
\hline Variables & SEMS $(n=72)$ & TDT $(n=44)$ & $P$ value* \\
\hline Surgical procedures & & & 0.26 \\
\hline $\begin{array}{l}\text { Primary } \\
\text { anastomosis } \\
(\%, n)\end{array}$ & $73.6(53)$ & $63.6(28)$ & \\
\hline $\begin{array}{l}\text { Tumor resection } \\
\text { after stomas } \\
(\%, n)\end{array}$ & $26.4(19)$ & $36.4(16)$ & \\
\hline Surgical time (min) & $162.0 \pm 56.8$ & $194.4 \pm 75.9$ & 0.01 \\
\hline $\begin{array}{l}\text { Postoperative } \\
\text { hospital-stay (day) }\end{array}$ & $\begin{array}{c}12.0 \\
(11.0,15.0)\end{array}$ & $\begin{array}{c}13.0 \\
(10.3,17.0)\end{array}$ & 1.00 \\
\hline $\begin{array}{l}\text { Total expenses } \\
\text { (RMB) }\end{array}$ & $\begin{array}{c}87,562 \\
(72,640,111,935)\end{array}$ & $\begin{array}{c}84,547 \\
(68,187,100,306)\end{array}$ & 0.26 \\
\hline $\begin{array}{l}\text { Anastomotic leak } \\
\text { rate }(\%, n)\end{array}$ & $0(0)$ & $2.3(1)$ & 0.20 \\
\hline
\end{tabular}

significantly shorter than that after TDT $(\mathrm{P}<0.01$, Table 3). Also, the time interval between SEMS/TDT insertion and surgery presented no significant difference (Table 3).

\section{Follow-up treatment}

In the SEMS group, 72 cases received surgical treatment, 15 cases received chemotherapy, and 48 cases received palliative treatment. In the TDT group, 44 patients received surgical treatment, 5 received chemotherapy, and 15 received palliative treatment (Figure 1). There was no significant difference between the 2 groups (Table 4).

\section{Post-operation conditions}

Operation time in the SEMS group and TDT group was
$162.0 \pm 56.8$ and $194.4 \pm 75.9$ minutes, respectively. Operation time was significantly shorter in SEMS than in TDT $(\mathrm{P}=0.01)$. There were no significant differences in postoperation conditions, including in one-stage anastomosis rate, postoperative hospital stay, and hospital cost, between SEMS and TDT (Table 5).

\section{Discussion}

The comparison of baseline data showed that malignant colorectal obstruction was higher in older adults, with an average age of 65 or older. In this research, the sigmoid colon is also the most common location of cancer, which is consistent with domestic and foreign literature (19). Recent research reports that the technical success rate of SEMS and TDT is more than $80 \%$ on average, with the success rate gradually increasing (20-22). The rates of the 2 groups in this study were $97.1 \%$ and $95.6 \%$, respectively. As the effective diameter of TDT is smaller than that of SEMS, dry feces at the obstruction are more likely to block the catheter in TDT, so the drainage speed and relief speed of the obstruction in TDT are slightly slower than those of SEMS. It has been reported that the average decompression period of TDT is 8 days, while the decompression period of SEMS is 2.2-5 days (21). Compared with the 12-day average decompression period of first-stage emergency colostomy (23), both the and SEMS the TDT have advantages in decompression speed, with the SEMS performing better. In our study, no direct comparison was made between the 2 groups of patients in terms of the time to relieve obstruction through catheters or stents. However, if the patients were fed orally, it could be inferred that the obstruction was relieved, and the exhaust and defecation were unobstructed. Therefore, the time of oral feeding can also represent the time when the catheter or stent can relieve the obstruction. In our research, the oral feeding time of patients in the SEMS group and TDT group was $2.4 \pm 1.5$ and $8.1 \pm 3.8$ days, respectively, which was consistent with the domestic and foreign research data and conclusions. Compared with TDT implantation, SEMS can quickly relieve the obstruction symptoms of the patients, which has a distinct time advantage $(\mathrm{P}<0.01)$. Furthermore, the complication rate of SEMS was significantly lower than that of TDT $(\mathrm{P}<0.05)$, with similar results been reported in other research centers (24-26).

Due to the bridging effect of SEMS and TDT, the obstruction was relieved, and intestinal edema was alleviated at the same time, which significantly increased 
the probability of one-stage anastomosis (end-to-end anastomosis) after tumor resection. The clinical success rate of both the SEMS group and TDT group was higher than $85 \%$, with no significant difference, indicating that both can effectively relieve the clinical symptoms of intestinal obstruction. The colostomy rate of TDT group (36.3\%) was higher than that of the SEMS group (26.4\%) in our research, but the difference was not statistically significant and may be related to the small sample size. Compared with the traditional staging surgery method, the stoma rate of the 2 methods was around $30 \%$, so the use of both methods can improve the rate of one-stage anastomosis in surgery. Although there was no statistically significant difference in postoperative hospitalization duration between the 2 groups, the operation time of the SEMS group was shorter than that of the TDT group $(\mathrm{P}=0.01)$. The research of Kinki University found that histopathologic edema was significantly more alleviated after the placement of SEMS than after the placement of TDT (5). Also, the colostomy rate of patients with a high level of intestinal edema was significantly higher than that of patients with a low level in our study. The short operation time of patients in the SEMS group was related to the fact that the stents could quickly relieve intestinal edema, thereby reducing the difficulty of intraoperative resection and anastomosis.

In our hospital, the cost of SEMS alone was about 20,000 renminbi (RMB), and the TDT cost was about 10,000 RMB. Excluding other tests unrelated to the disease, the total treatment cost of patients receiving surgery in the SEMS group and TDT group averaged 87,562 RMB and $84,547 \mathrm{RMB}$, respectively $(\mathrm{P}=0.26)$. Although the cost of endoscopic operation alone varies greatly, SEMS can rapidly improve the condition of intestinal obstruction, while shortened hospitalization time (before and after surgery) can also reduce part of the hospitalization costs. Therefore, there was no significant difference in total treatment cost between the SEMS group and TDT group.

Some patients with advanced tumors have multiple metastases or surgical contraindications, so alleviating obstruction symptoms, improving the quality of life, and prolonging the survival period as far as possible has become the focus of treatment.

For patients with lower rectal obstruction, SEMS may irritate the rectal mucosa, so TDT is preferred. However, long-term TDT indwelling is not convenient for the patients' daily activities and results in discomfort from the friction of the anus, which affects the independent defecation and increases the difficulty of nursing.
Therefore, for patients with palliative cancer treatment, SEMS implantation is more accepted. However, according to the studies of other institutions, some patients receiving palliative care for cancer who continue to receive radiotherapy and chemotherapy after receiving SEMS treatment may experience tumor shrinkage, stent displacement, and shedding, so the necessity of operation should be weighed more carefully for these patients.

Also, SEMS may cause tumor damage while expanding and pressing the tumor. As the tumor itself is a tissue rich in blood supply, cells entering the blood can accelerate the multi-organ metastasis of the tumor. Some researchers believe that when SEMS is used as a bridge for surgery $(27,28)$, it can induce tumor proliferation and reduce the long-term survival rate. At the same time, studies have suggested that the 5 -year survival rate of patients treated with SEMS is lower than that of patients undergoing emergency surgery (29). However, several studies have concluded that there is no significant difference in the longterm tumor recurrence rate between patients receiving SEMS and those undergoing emergency surgeries. The comparative measure of circulating tumor cells before and after SEMS implantation has a specific significance. In Japan, research in this vein concluded that SEMS increases the risk of tumor metastasis to some extent. Meanwhile, whether SEMS treatment will affect the long-term survival rate of patients with malignant colorectal cancer remains to be studied.

In conclusion, with safe and reliable results, both SEMS and TDT can effectively relieve the acute malignant left colorectal obstruction. Short-term efficacy can be confirmed, but long-term efficacy still requires more extended follow-up observation. Compared with traditional staging surgery, both methods can effectively reduce the colostomy rate, providing a bridge for the selective surgery of patients with acute left malignant colorectal obstruction, with SEMS being a little faster. However, consideration for the conclusion of this study should also take into account its small, non-randomized, retrospective design, which limits its generalizability. In the future, further prospective clinical studies are required.

\section{Acknowledgments}

We thank the Department of Gastroenterology of First Hospital of China Medical University.

Funding: This work was supported by National Science Foundation of China (81670506). 


\section{Footnote}

Reporting Checklist: The authors have completed the STROBE Reporting Checklist. Available at http:// dx.doi.org/10.21037/apm-19-458

Data Sharing Statement: Available at http://dx.doi. org/10.21037/apm-19-458

Conflicts of Interest: All authors have completed the ICMJE uniform disclosure form (available at http://dx.doi. org/10.21037/apm-19-458). The authors have no conflicts of interest to declare.

Ethical Statement: The authors are accountable for all aspects of the work in ensuring that questions related to the accuracy or integrity of any part of the work are appropriately investigated and resolved. The trial was conducted in accordance with the Declaration of Helsinki (as revised in 2013). Our study obtained ethics approval of Regional and Institutional Human Medical Biological Research Ethics Committee of China Medical University (No. AF-SOP-07-1).

Open Access Statement: This is an Open Access article distributed in accordance with the Creative Commons Attribution-NonCommercial-NoDerivs 4.0 International License (CC BY-NC-ND 4.0), which permits the noncommercial replication and distribution of the article with the strict proviso that no changes or edits are made and the original work is properly cited (including links to both the formal publication through the relevant DOI and the license). See: https://creativecommons.org/licenses/by-nc-nd/4.0/.

\section{References}

1. Bray F, Ferlay J, Soerjomataram I, et al. Global cancer statistics 2018: GLOBOCAN estimates of incidence and mortality worldwide for 36 cancers in 185 countries. CA Cancer J Clin 2018;68:394-424.

2. Deans GT, Krukowski ZH, Irwin ST. Malignant obstruction of the left colon. Br J Surg 1994;81:1270-6.

3. Frago R, Ramirez E, Millan M, et al. Current management of acute malignant large bowel obstruction: a systematic review. Am J Surg 2014;207:127-38.

4. Donlon NE, Kelly ME, Narouz F, et al. Colonic stenting as a bridge to surgery in malignant large bowel obstruction: oncological outcomes. Int J Colorectal Dis
2019;34:613-9.

5. Takeyama H, Kitani K, Wakasa T, et al. Self-expanding metallic stent improves histopathologic edema compared with transanal drainage tube for malignant colorectal obstruction. Dig Endosc 2016;28:456-64.

6. Baer C, Menon R, Bastawrous S, et al. Emergency Presentations of Colorectal Cancer. Surg Clin North Am 2017;97:529-45.

7. Rodrigues-Pinto E, Morais R, Coelho C, et al. Bridgeto-surgery versus emergency surgery in the management of left-sided acute malignant colorectal obstruction Efficacy, safety and long-term outcomes. Dig Liver Dis 2019;51:364-72.

8. Young CJ, Zahid A. Randomized controlled trial of colonic stent insertion in non-curable large bowel obstruction: a post hoc cost analysis. Colorectal Dis 2018;20:288-95.

9. Pearce NW, Scott SD, Karran SJ. Timing and method of reversal of Hartmann's procedure. Br J Surg 1992;79:839-41.

10. Peev MP, Yeh DD, Quraishi SA, et al. Causes and consequences of interrupted enteral nutrition: a prospective observational study in critically ill surgical patients. JPEN J Parenter Enteral Nutr 2015;39:21-7.

11. Shigeta K, Baba H, Yamafuji K, et al. Outcomes for patients with obstructing colorectal cancers treated with one-stage surgery using transanal drainage tubes. J Gastrointest Surg 2014;18:1507-13.

12. Arezzo A, Passera R, Lo Secco G, et al. Stent as bridge to surgery for left-sided malignant colonic obstruction reduces adverse events and stoma rate compared with emergency surgery: results of a systematic review and meta-analysis of randomized controlled trials. Gastrointest Endosc 2017;86:416-26.

13. Tanaka T, Furukawa A, Murata K, et al. Endoscopic transanal decompression with a drainage tube for acute colonic obstruction: clinical aspects of preoperative treatment. Dis Colon Rectum 2001;44:418-22.

14. Lee HJ, Hong SP, Cheon JH, et al. Clinical Outcomes of Self-Expandable Metal Stents for Malignant Rectal Obstruction. Dis Colon Rectum 2018;61:43-50.

15. Kawachi J, Kashiwagi H, Shimoyama R, et al. Comparison of efficacies of the self-expandable metallic stent versus transanal drainage tube and emergency surgery for malignant left-sided colon obstruction. Asian J Surg 2018;41:498-505.

16. Ohnita K, Shikuwa S, Isomoto H, et al. A new thin endoscopic method of transanal drainage tube insertion for acute colonic obstruction due to colorectal cancer. Dig 
Endosc 2009;21:252-4.

17. Cetinkaya E, Dogrul AB, Tirnaksiz MB. Role of self expandable stents in management of colorectal cancers. World J Gastrointest Oncol 2016;8:113-20.

18. Ormando VM, Palma R, Fugazza A, et al. Colonic stents for malignant bowel obstruction: current status and future prospects. Expert Rev Med Devices 2019;16:1053-61.

19. Wang FG, Bai RX, Yan M, et al. Short-Term Outcomes of Self-Expandable Metallic Stent versus Decompression Tube for Malignant Colorectal Obstruction: A MetaAnalysis of Clinical Data. J Invest Surg 2019:1-9. [Epub ahead of print].

20. Li CY, Guo SB, Wang NF. Decompression of acute left-sided malignant colorectal obstruction: comparing transanal drainage tube with metallic stent. J Clin Gastroenterol 2014;48:e37-42.

21. Sebastian S, Johnston S, Geoghegan T, et al. Pooled analysis of the efficacy and safety of self-expanding metal stenting in malignant colorectal obstruction. Am J Gastroenterol 2004;99:2051-7.

22. Wang FG, Yan WM, Yan M, et al. Outcomes of transanal tube placement in anterior resection: A meta-analysis and systematic review. Int J Surg 2018;59:1-10.

23. Varadarajulu S, Roy A, Lopes T, et al. Endoscopic stenting versus surgical colostomy for the management of malignant colonic obstruction: comparison of hospital

Cite this article as: An Y, Wang N, Yang Z, Li Y, Xu B, Guo G, Sun M. Efficacy of transanal drainage tube and selfexpanding metallic stent in acute left malignant colorectal obstruction. Ann Palliat Med 2020;9(4):1614-1621. doi: 10.21037/apm-19-458 costs and clinical outcomes. Surg Endosc 2011;25:2203-9.

24. Matsuda A, Miyashita M, Matsumoto S, et al. Comparison between metallic stent and transanal decompression tube for malignant large-bowel obstruction. J Surg Res 2016;205:474-81.

25. Sato R, Oikawa M, Kakita T, et al. Comparison of the long-term outcomes of the self-expandable metallic stent and transanal decompression tube for obstructive colorectal cancer. Ann Gastroenterol Surg 2019;3:209-16.

26. Matsuda A, Yamada T, Matsumoto S, et al. Short-term outcomes of a self-expandable metallic stent as a bridge to surgery vs. a transanal decompression tube for malignant large-bowel obstruction: a meta-analysis. Surg Today 2019;49:728-37.

27. van Hooft JE, Bemelman WA, Oldenburg B, et al. Colonic stenting versus emergency surgery for acute left-sided malignant colonic obstruction: a multicentre randomised trial. Lancet Oncol 2011;12:344-52.

28. Thorlacius H. Tumour cell dissemination following endoscopic stent insertion (Br J Surg 2007; 94: 11511154). Br J Surg 2008;95:127-8; author reply 128.

29. Sabbagh C, Browet F, Diouf M, et al. Is stenting as "a bridge to surgery" an oncologically safe strategy for the management of acute, left-sided, malignant, colonic obstruction? A comparative study with a propensity score analysis. Ann Surg 2013;258:107-15. 